\title{
Anatomical differentiation and metabolomic profiling: a tool in the diagnostic characterization of some medicinal Plantago species
}

\author{
Leonardo Mendes de Souza Mesquita ${ }^{1}$ - Karine Delevati Colpo ${ }^{2,3} \cdot$ \\ Cláudia Quintino da Rocha ${ }^{4} \cdot$ Douglas Gatte-Picchi ${ }^{1}$. \\ Marcelo Marucci Pereira Tangerina ${ }^{1}$ - Beatriz Zachello-Nunes ${ }^{1}$. \\ Maria Bernadete Gonçalves Martins ${ }^{1} \cdot$ Wagner Vilegas ${ }^{1}$
}

Received: 13 October 2016/Accepted: 6 April 2017/Published online: 18 April 2017

(C) Botanical Society of Sao Paulo 2017

\begin{abstract}
There is a large list of plants used by the population as medicine, but in some case the choice of the right plant becomes a real drawback in phytotherapy, since it is often difficult to differentiate morphologically between the active and inactive species. Plantago species are widely used throughout the world as analgesic, anti-inflammatory, expectorant, digestive and wound healing. Nonetheless, Plantago spp. share very strong morphological similarities, which hinders their correct botanical identification and, in addition, they are equivocally marketed by the same common name "Plantain". Therefore, the establishment of a reliable approach to distinguish unambiguously closely related species arises as an important task in the development of herbal medicines. In this work, we report a method that combines anatomical leaf features and chemical composition of four Plantago species to generate a
\end{abstract}

Electronic supplementary material The online version of this article (doi:10.1007/s40415-017-0388-x) contains supplementary material, which is available to authorized users.

Leonardo Mendes de Souza Mesquita

mesquitalms@gmail.com

$\triangle$ Wagner Vilegas

vilegasw@gmail.com

1 Biosciences Institute, Laboratory of Bioprospection of Natural Products (LBPN), São Paulo State University (UNESP), Pça Infante Dom Henrique S/N, São Vicente, São Paulo CEP 11330-900, Brazil

2 Institute of Limnology Dr. Raúl A. Ringuelet (CONICETUNLP), CC 712, 1900 La Plata, Argentina

3 Consejo Nacional de Investigación, Científicas y Técnicas (CONICET-CCT, La Plata), La Plata, Argentina

4 Department of Chemistry, Federal University of Maranhão (UFMA), Avenida dos Portugueses 1966, São Luís, Maranhão 65085-580, Brazil multivariate model, which allows the differentiation of these species. Descriptive leaf anatomy was converted into a binary matrix to create a qualitative/quantitative nonmetric multidimensional scaling (nmMDS) based on Jaccard index. The main results show that $P$. lanceolata $\mathrm{L}$. is the most distinct species, the only one that owns mesophyll isolateral, colateral vascular bundle and a glandular trichome with spindle cells. Plantago major L. also has a unique glandular trichome, with enlarged basal cell and collar cell. This statistical-based anatomical approach is suitable to solve similar drawbacks in plant medicines of any other plant-cases. In addition, it was generated a nmMDS to chemical markers by mass spectrometry (FIAESI-IT-MS), to define how similar the species are regarding their chemical composition. Plantago major showed all compounds evaluated and is the only species to have the compounds hellicoside $(\mathrm{m} / \mathrm{z} 655)$ and lavandulifolioside $(\mathrm{m} / \mathrm{z} 755)$. The conversion of anatomical features into statistical data with the chemical composition emerges as a useful approach toward the quantitative differentiation of morphologically close related specimens.

Keywords Leaf anatomy - Mass spectrometry ·

Multivariate analyses - Plantain $\cdot$ Thricome

\section{Introduction}

Several forms of traditional medicine flourished independently in many civilizations, based on their ethnopharmacological knowledge (Halberstein 2005; Na-Bangchang and Karbwang 2014). The role of these forms of medicine, often mistakenly called complementary, is essential today for the health treatment of many communities. Safety criteria must ensure the adequate measures to protect the 
public health, since $80 \%$ of the world's population relies mainly on traditional methods of treatment (Ekor 2013).

The study of medicinal plants is characterized by a multidisciplinary approach, merging several aspects of chemistry and biology to unravel their therapeutic potential. The use of many plants in folk medicine is supported by a long history of applications and empirical observations of their toxic and medicinal effects (Moreira et al. 2014). However, in some cases, morphologically similar species are used without any differentiation criteria, sometimes even having different therapeutic potential (Garg et al. 2012).

In this context, the differentiation of morphologically similar species, but with different therapeutic potentials, is a pivotal approach already in the initial stages of development of a phytotherapic. The development of combined techniques based on comparative analysis of plants with therapeutic potential can be a promising and reliable strategy for differentiation of species that are morphologically similar and also very close taxonomically (Atanasov et al. 2015). Many studies have shown the great potential as source of bioactive compounds of plantain species (Plantago genus) (Ozkan et al. 2016; Mesquita et al. 2017). They are known as producers of iridoids, phenylethanoid glycosides, carotenoids, and therefore are a good source of antioxidants and nutraceutical compounds (Samuelsen 2000).

A comparative study was developed based on detailed anatomical description of the leaves and metabolomic profiles of four Plantago species (P. major L., P. australis L., $P$. lanceolata L. and $P$. catharinea L.) —all popularly known as "Plantain"-which are commonly used worldwide in the traditional medicine to treat a plethora of diseases and disorders (Table 1). These plants have been used for medical purpose by the popular traditional medicine since 1592 (Samuelsen 2000). The aim of this study was: (1) to evaluate the leaf anatomy and chemical composition of four species of Plantago and (2) to check how similar the species are, in order to search distinctive characters of these species.

\section{Materials and methods}

Plant material - Four species of Plantago (P. major, $P$. australis L., $P$. lanceolata and $P$. catharinea L.) were chosen because of their morphological similarities, which in consequence cause misunderstanding in their correct identification. The specimens were collected in reproductive stage in the Garden of Medicinal Plants of Botucatu (UNESPBrazil), under the same climate and edaphic conditions. Plants from the same place were collected to avoid phenotypic variations influenced by habitat differences. Mature leaves from ten plants of each species were used for the analysis of anatomical and chemical parameters. The voucher specimens were deposited and registered at the Herbarium ESA at São Paulo University/USP (Table 1).

Anatomical parameters - Ten leaf samples (central portion of the leaf, including rib and mesophyll) were fixed in $70 \%$ FAA solution (1:1:18 formaldehyde, glacial acetic acid and ethyl alcohol 70\%) (Johansen 1940), dehydrated by serial washes of ethanol and infiltrated in historesin $\left(\right.$ Leica $\left.^{\circledR}\right)$. In a rotary microtome $\left(\right.$ Leica $\left.^{\circledR}\right)$, the blocks were transversally sectioned ( $\mu \mathrm{m}$ thick), stained with toluidine blue $\mathrm{O}$ and mounted in synthetic medium Entellan ${ }^{\circledR}$ for cover slippers (O’Brien et al. 1964; Sakai 1973). The slides were analyzed by light microscopy (Zeiss Primo Star).

Table 1 Origin, distribution and medicinal use of Plantago spp

\begin{tabular}{|c|c|c|c|c|}
\hline Species & Distribution & $\begin{array}{l}\text { Voucher } \\
\text { numbers }\end{array}$ & $\begin{array}{l}\text { Reported medicinal } \\
\text { use }\end{array}$ & Reference \\
\hline Plantago major & Cosmopolitan & ESA 119208 & $\begin{array}{l}\text { Analgesic } \\
\text { Anti-inflammatory } \\
\text { Digestive } \\
\text { Wound healing }\end{array}$ & Samuelsen (2000) \\
\hline Plantago australis & $\begin{array}{l}\text { Widely distributed in Argentina and south of } \\
\text { Brazil }\end{array}$ & ESA 119210 & $\begin{array}{l}\text { Analgesic } \\
\text { Anti-inflammatory }\end{array}$ & Hefler et al. (2011) \\
\hline $\begin{array}{l}\text { Plantago } \\
\text { lanceolata }\end{array}$ & Cosmopolitan & ESA 119209 & $\begin{array}{l}\text { Analgesic } \\
\text { Anti-inflammatory } \\
\text { Diuretic } \\
\text { Expectorant } \\
\text { Cicatrizing }\end{array}$ & $\begin{array}{l}\text { Hefler et al. (2011) } \\
\text { Makhmudov et al. (2011) }\end{array}$ \\
\hline $\begin{array}{l}\text { Plantago } \\
\text { catharinea }\end{array}$ & Brazilian coastal regions & ESA 120487 & Antioxidant & Mesquita et al. (2017) \\
\hline
\end{tabular}


For each species of Plantago, the epidermal cells, cuticle, mesophyll cells, stomata, midrib, vascular bundle of the midrib, glandular trichomes and tectory trichomes present in the leaves were characterized in detail. In addition, the height and diameter of the midrib and of the main vascular bundle, and the height of leaf mesophyll were measured (in $\mu \mathrm{m}$ ) by an imager coupled to the microscope and AxionVision software (Zeiss). Subsequently, these images were scanned by image analysis system (AxionVision-Zeiss), utilized for the making of histological templates.

The details of some anatomical parameters and the density of leaf epidermal structures (stomata, glandular and tector trichomes) were analyzed by scanning electron microscopy (SEM). The leaves were fixed in modified Karnovsky solution consisting of $4 \%$ paraformaldehyde, $0.5 \%$ glutaraldehyde in sodium cacodylate buffer, $\mathrm{pH} 7.2$, $0.1 \mathrm{M}$, and distilled water for one night in vacuum. The material was dehydrated by serial washes of acetone, critical point dried up and then metallized with gold (Danilatos 1988). The analysis was performed using a ZeissDSM 940SEM at the Centro de Energia Nuclear na Agricultura (CENA) in Esalq USP (Piracicaba-São Paulo).

The density of the epidermal structures was estimated by imaging with the magnitude of $\times 1000$, which provided the quantification of structures in 20 random fields of three different plants $\left(230,400 \mu \mathrm{m}^{2}-10\right.$ fields to abaxial side and 10 for adaxial), for each species studied. The biometric data (height and diameter of the midrib, height and diameter of the main vascular bundle and height of the leaf mesophyll) and stomata, glandular and tectory trichomes density were compared among the different Plantago species studied by analysis of variance for parametric data (post hoc Tukey tests were applied for multiple comparisons) and equivalent Kruskal-Wallis test for nonparametric data (post hoc Dunn tests were applied for multiple comparisons). To compare the density of epidermal structures between different leaf sides of the same plant, the Student's $t$ hypothesis test was used for parametric data, and the Mann-Whitney test was used for nonparametric data. The homogeneity of variances was tested using Levene's test.

To answer how similar anatomically species are, a matrix of presence (1) and absence (0) of characteristics was constructed based on the descriptive results of each species, as well as the biometric data. The set of qualitative and quantitative anatomical characteristics observed was compared among the Plantago species by non-metric multidimensional scaling analysis, using the Jaccard coefficient of similarity that describes how similar the species are in terms of shared characteristics (presence/absence) (adapted from Gotelli and Ellison 2013).
Chemical parameters - The chemical profiles of the Plantago species were obtained by mass spectrometry of the ethanolic extract (70\% ethanol). For each species, an extract was prepared by combining leaves from ten different plants. Extracts were prepared using $200 \mathrm{~g}$ of dried leaves, dried in a circulated air incubator at $45{ }^{\circ} \mathrm{C}$ for 7 days. The material was then reduced to powder in a grinding mill and stored in amber glass bottles. Subsequently, $50 \mathrm{~g}$ of powder was swollen in $500 \mathrm{~mL}$ of extraction solvent (70\% ethanol) for $2 \mathrm{~h}$ (Prista 1995). Then, the percolator was homogeneously packed with the mixture (powder $+70 \%$ ethanol) and the effluent was collected at a flow rate of $1.0-2.0 \mathrm{~mL} \mathrm{~min}^{-1}$ ). After extraction, the solvent was dried under reduced pressure at $40{ }^{\circ} \mathrm{C}$ in a rotary evaporator. The extracts were transferred to vials and dried in a fume hood until complete solvent removal. Finally, to obtain the chemical profile of the Plantago species, the extracts were subjected to mass spectrometry analysis (FIA-ESI-IT-MS). Flow injection analysis (FIA) was performed using a Thermo Fisher Scientific ion trap mass spectrometer (San Jose, CA, USA) equipped with an electrospray ionization source, flow rate of $5 \mu \mathrm{L} \mathrm{min}{ }^{-1}$ and working under the following conditions: capillary voltage $-31 \mathrm{~V}$, spray voltage $5 \mathrm{kV}$, tube lens offset $75 \mathrm{~V}$, capillary temperature $300{ }^{\circ} \mathrm{C}$, sheath gas $\left(\mathrm{N}_{2}\right)$ flow rate 8 (arbitrary units). Negative ion mass spectra were recorded in the range $m / z, 100-2000 \mathrm{Da}$. The first event was a full-scan mass spectrum to acquire data on ions in the $m / z$ range. The second scan event was an MS/MS experiment performed by using data-dependent scan that was carried out on deprotonated molecules from the compounds at collision energy of $30 \%$ and activation time of $30 \mathrm{~ms}$. Data acquisition and processing were performed using the Xcalibur software. The mass/charge $(\mathrm{m} / \mathrm{z})$ was the criterion for distinguishing for each molecule detected in the analyses. A matrix of presence (1) and absence (0) of chemical markers was constructed to prepare a non-metric multidimensional scaling (nmMDS). The data in this matrix were subjected to the similarity analysis, conducted by Jaccard coefficient of similarity that describes how similar the species are in terms of shared chemical markers (adapted from Gotelli and Ellison 2013).

\section{Results}

We have accomplished an anatomical and chemical analysis of the four species of Plantago. These results prove that while these plants are similar to each other (about 60\% similarity to all anatomical investigated characters), they do not display the same pattern of chemical markers, since the four species are grouped with low similarity. 
Epidermal cells - The epidermis is uniseriate, consisting of cells with irregular shapes, with the same pattern in abaxial and adaxial face (Figs. 2, 4, 6, 7). The periclinal cell wall is thin, while the anticline one is slightly thicker (Figs. 2, 4, 6, 7).
The epidermal cells observed by scanning electron microscopy have a similar size and isodiametric shape for all Plantago species studied (Figs. 9, 11, 12, 14). However, $P$. major have difference on anticline wall format when compared abaxial and adaxial faces. The abaxial
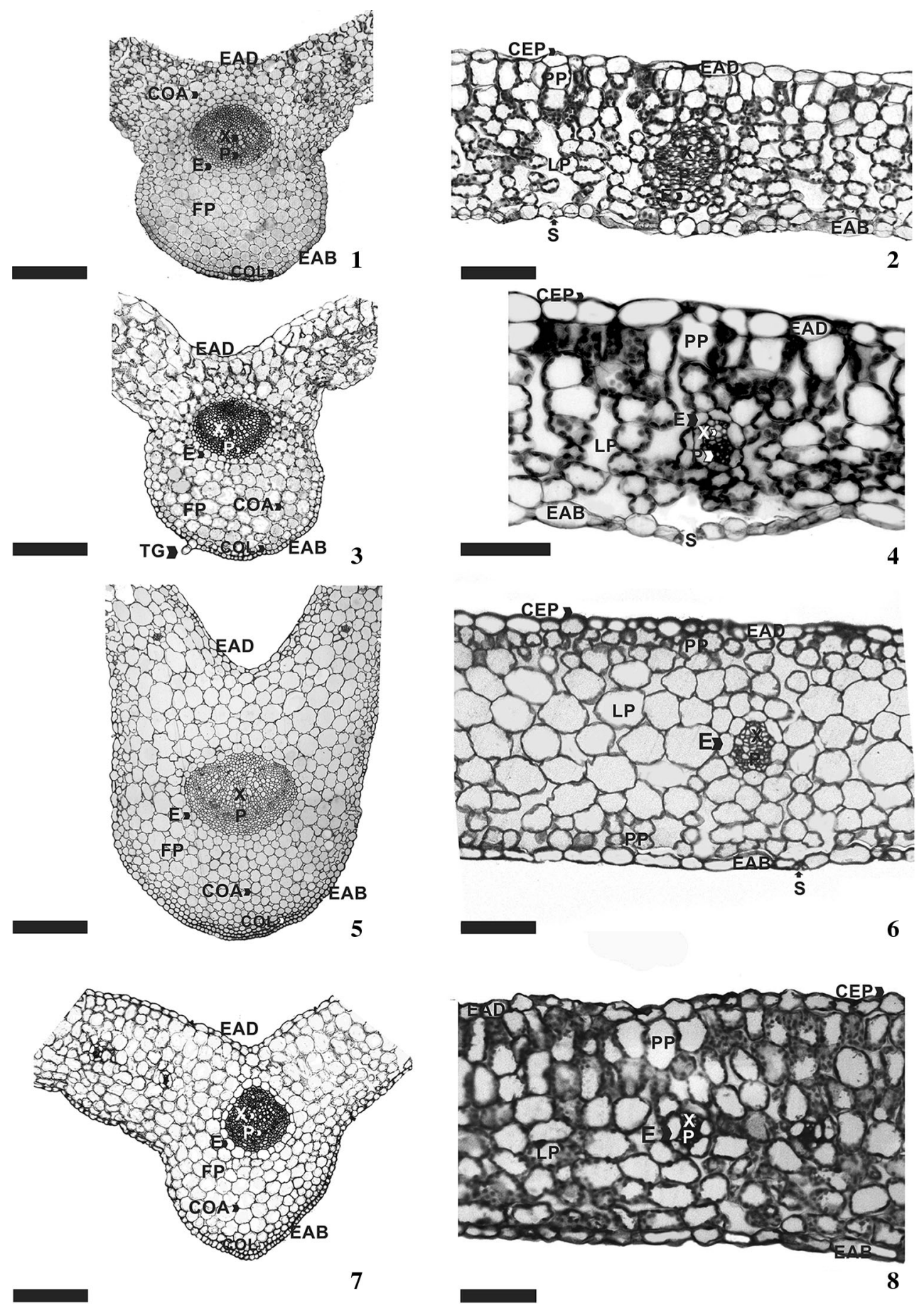

Figs. 1-8 Cross sections of the leaf blade of four Plantago species. 1 Central rib of $P$. major; 2 mesophyll of $P$. major; 3 central rib of $P$. australis; $\mathbf{4}$ mesophyll of $P$. australis; $\mathbf{5}$ central rib of $P$. lanceolata; $\mathbf{6}$ mesophyll of $P$. lanceolata; $\mathbf{7}$ Central rib of $P$. catharinea; $\mathbf{8}$ mesophyll of $P$. catharinea. To 1, 3, 5 and $710 \times /$ scale: $100 \mu \mathrm{m}$; To 2, 6 and 8: $20 \times /$ scale: $50 \mu \mathrm{m}$; To 4: $40 \times / 30 \mu \mathrm{m}$. EAD adaxial epidermis, EAB abaxial epidermis, $C E P$ epicuticular wax, $C O A$ angular collenchyma, $C O L$ lamellar collenchyma, $E$ endoderm, $S$ stomata, $P$ phloem, $F P$ fundamental parenchyma, $L P$ spongy parenchyma, $P P$ palisade parenchyma, $T G$ glandular trichomes 

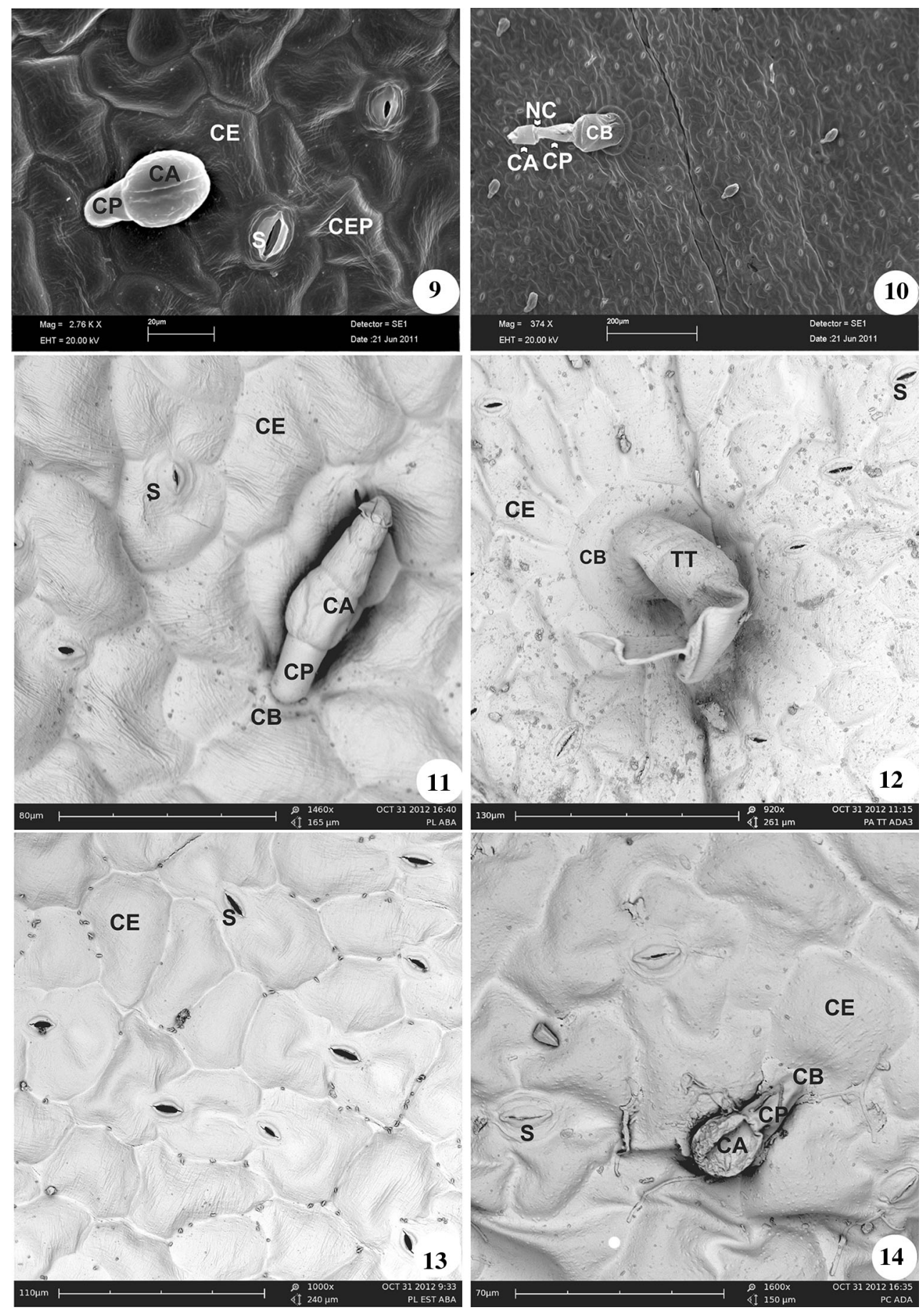

Figs. 9-14 Scanning electron micrograph of leaf epidermal structures of Plantago species. 9 capitate trichomes present on the adaxial surface of $P$. major $(2,76 \mathrm{KX})$; $\mathbf{1 0}$ abaxial surface of $P$. major, capitate trichomes with necklace cell $(\times 374)$; $\mathbf{1 1}$ exclusive capitate trichome of $P$. lanceolata present on the abaxial epidermis $(\times 1460)$; 12 non-glandular trichome (tector) in $P$. australis present in the adaxial epidermis $(\times 920)$; 13 abaxial surface of $P$. lanceolata, detail of anomocytic stomata $(\times 1000) ; \mathbf{1 4}$ adaxial surface of $P$. catharinea capitate glandular and anomocytic stomata $(\times 1600)$. $C P$ stalk cell, $C A$ apical cell, $C E$ epidermal cell, $C E P$ epicuticular wax, $S$ stomata, $N C$ necklace cell, $T T$ tectory trichomes

epidermis has anticline sinuous wall (Fig. 2), while the upper side presents straight anticlinal wall (Fig. 2). In $P$. australis has straight anticlinal wall in both leaf surfaces (Fig. 4) and in P. lanceolata and P. catharinea were observed on the abaxial and adaxial epidermis surfaces (Figs. 6, 8).

Cuticle - All four species have thin epicuticular wax with slightly striated deposition on both epidermal surfaces 
Tabel 2 Features of the leaf mesophyll

\begin{tabular}{lllll}
\hline Features & $P$. major & $P$. australis & $P$. lanceolata & $P$. catharinea \\
\hline Type & Dorsiventral & Dorsiventral & Isolateral & Dorsiventral \\
Layers of palisade parenchyma & $2-3$ & $1-2$ & $1-2$ & $2-3$ \\
Layers of spongy parenchyma & $6-7$ & $5-6$ & $6-7$ & $5-6$ \\
\hline
\end{tabular}

(abaxial and adaxial) (Figs. 9, 11, 12, 14). It was observed that all species in this study have a cuticle thickness at the adaxial face of epidermal cells, than the cuticle on the abaxial surface (Figs. 2, 4, 6, 8).

Mesophyll - The species analyzed have dorsiventral mesophyll type, except for $P$. lanceolata which has isolateral mesophyll with palisade parenchyma in both leaf surfaces (Figs. 2, 4, 6, 8), and its characteristics are described in Table 2.

Stomata - The leaves of Plantago species in this study are amphistomatic, and the stomata are anomocytic, with three/four isodiametric cells, which are usually inserted at the same level of epidermal cells (Figs. 9, 12, 13, 14).

Plantago major and $P$. catharinea have a higher density of stomata in the abaxial epidermis than $P$. lanceolata and $P$. australis (Table S1). The same pattern does not occur in the upper side, because $P$. major has more stomata per area than the other species (Table S1). When comparing the number of stomata in abaxial and adaxial epidermal in each species, it is found that stomatal density on the abaxial epidermis was higher in all species studied ( $t$ test: $P<0.05$ ).

Central rib - The four species showed concave-convex central rib, prominent being on the abaxial surface (Figs. 2, $4,6,7)$. Underlying uniseriate epidermis on the abaxial surface of the main rib, there is the presence of lamellar collenchyma, but the rest of the fundamental parenchyma is composed of angular chlorenchyma (Figs. 2, 4, 6, 7). The fundamental parenchyma cells have a rounded shape, with thin walls and small intercellular spaces between them (Figs. 1, 3, 5, 7). The height and the diameter of the central rib are bigger in $P$. lanceolata compared with the other three species (Table S2).

Vascular bundle of central rib - Plantago major, $P$. australis and $P$. catharinea have bicollateral vascular bundle (Figs. 1, 3, 7), but $P$. lanceolata has collateral vascular bundle (Fig. 5). The vascular bundle of $P$. lanceolata also differs from other species in size because it has bigger height and diameter (Table S2). Around the vascular bundle, there is an endodermal, with single layer of cells in all studied species.

Glandular trichomes - Glandular trichomes were found on both sides of the leaf epidermis of all species. Plantago catharinea had the highest and P. lanceolata the lowest density of glandular trichomes on the abaxial surface
(Table S1). Plantago major and $P$. australis have intermediate amounts of these structures (Table S1). In addition, no differences were observed for each species regarding their amount of glandular trichomes on both epidermal abaxial and adaxial surfaces $(t$ test: $P>0.05)$ (Table S1). In both leaf faces of the four species, a capitate trichome was identified, which is inserted in four radially disposed epidermal cells, has a stalk cell and gland consisting of two ellipsoidal shape apical cells (Figs. 9, 14).

Plantago lanceolata has a glandular type of an exclusive capitate trichome that does not occur in other evaluated species. This trichome is found in both leaf surfaces, which consists of an epidermal basal cell, a stalk cell and apex with comprising multiple spindle glandular apical cells (Fig. 11). Exclusive in P. major, capitate trichome with several radially arranged epidermal basal cells with an enlarged basal cell, a narrow stalk cell, a collar cell and an apical cell (Fig. 10).

Tectory trichomes - In all species were found only one type of tectory trichomes in both leaf surfaces. Uniseriate trichomes and multicellular tectory unbranched and tapering from base to apex is pointed to the end cell, with the smooth wall (Fig. 11). In the four species in both leaf surfaces, there is no difference in the amount of this structure $(t$ test: $P>0.05)$.

Similarities among Plantago species, based on their anatomical features - The nmMDS analysis, for qualitative and quantitative anatomical parameters, constructed from the binary matrix of presence and absence (Table S3) shows that the plants are grouped by $60 \%$ of similarity to each other. Plantago major and P. catharinea are the species with the highest similarity, sharing about $67 \%$ of their features (Jaccard coefficient of similarity) (Fig. 15). While $P$. australis and P. lanceolata do not group with the others, the exact similarity between each evaluated species is presented in Fig. 15. Plantago lanceolata showed a set of distinctive characteristics from the other three species, such as height and diameter of the midrib, height and diameter of the vascular bundle, high of the mesophyll, glandular trichomes with the presence of spindle gland, isolateral mesophyll, colateral vascular bundle, and the number of glandular trichomes in adaxial surface. This result shows that these species share most of the features (qualitatives and quantitatives) analyzed in this study, and therefore are easily confused. 
Fig. 15 Non-metric multidimensional scaling of Plantago species, founded on qualitative and quantitative anatomic parameters, based on Jaccard similarity index
Fig. 16 Non-metric multidimensional scaling to chemical markers of Plantago species, based on Jaccard similarity index
Transform: Presencelabsence Resemblance: S7 Jaccard

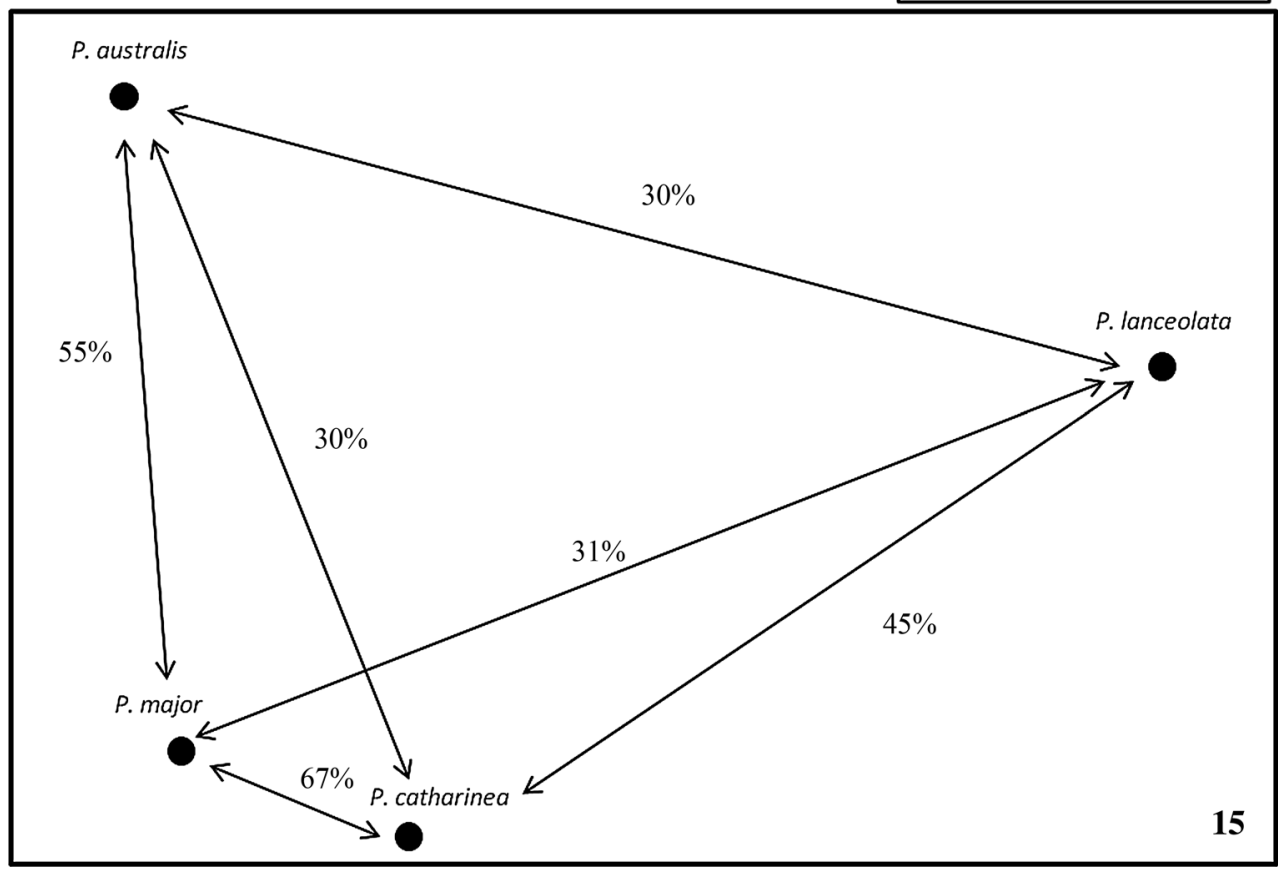

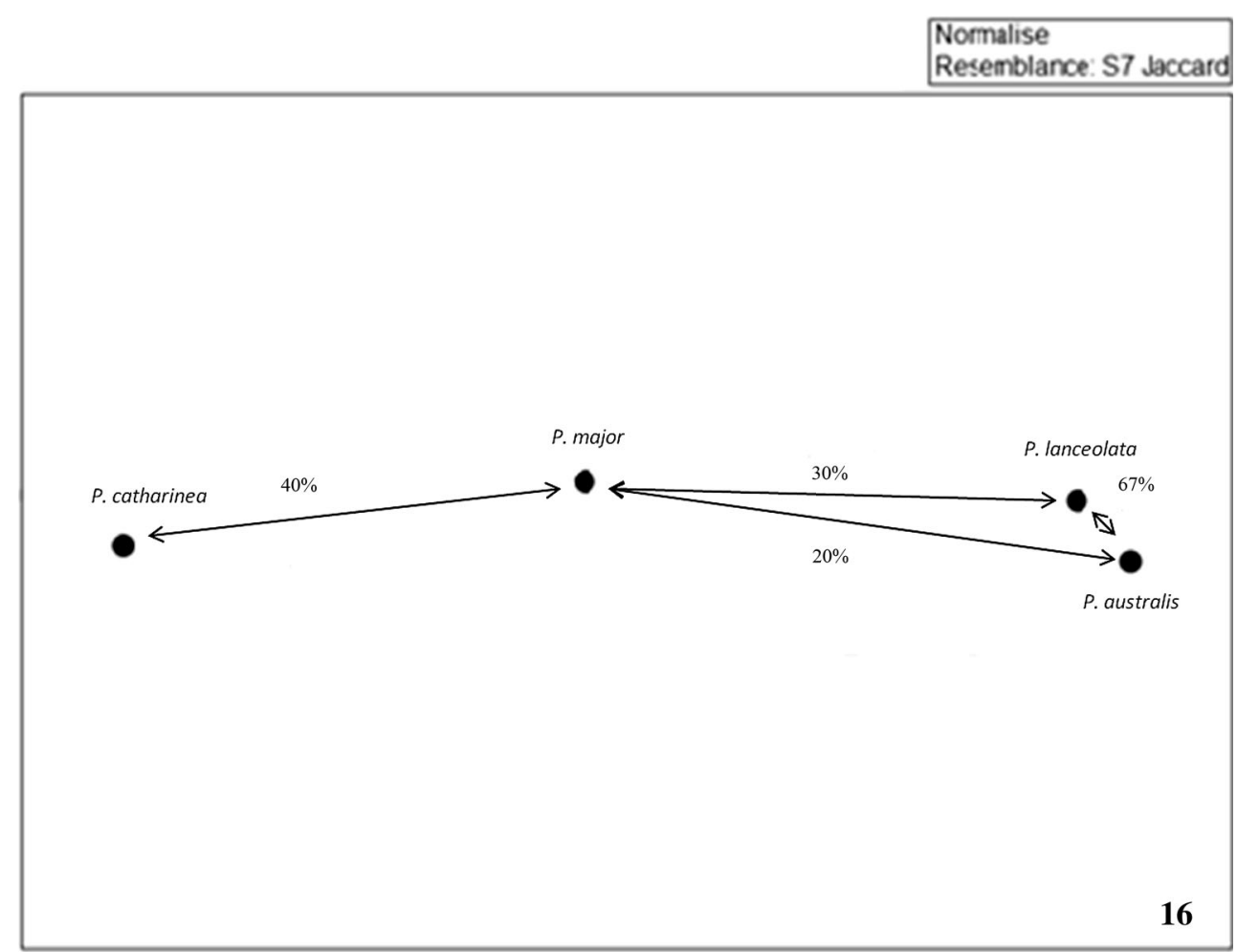

Chemical parameters - FIA-ESI-IT-MS analysis was performed to recognize the main class of compounds. The major classes of compounds found in the four species were flavonoids, iridoid glycosides and phenylethanoid glycosides (Fig. 16). The presence and absence of these metabolites was the criterion used to build the matrix of chemical markers (Table 3), and generate the nmMDS. Plantago major have all identified chemical markers (Table 3). Plantago australis has only five markers, all of the compounds of the class phenylethanoid glycosides 
Table 3 Binary matrix of chemical markers of Plantago species

\begin{tabular}{llllll}
\hline$M / z$ & Compound & $\mathrm{Pm}$ & $\mathrm{Pa}$ & $\mathrm{Pl}$ & $\mathrm{Pc}$ \\
\hline 269 & Apigenin & 1 & 0 & 1 & 0 \\
301 & Quercetin & 1 & 0 & 0 & 0 \\
345 & Aucubin & 1 & 0 & 0 & 1 \\
477 & Dershamnosylacteoside & 1 & 0 & 0 & 1 \\
609 & Rutin & 1 & 0 & 0 & 1 \\
621 & Crenatoside & 1 & 0 & 0 & 1 \\
623 & Acteoside & 1 & 1 & 1 & 0 \\
637 & Methyl acteoside & 1 & 1 & 1 & 0 \\
639 & Plantamajoside & 1 & 1 & 1 & 1 \\
653 & Methyl-plantamajoside & 1 & 1 & 1 & 1 \\
655 & Hellicoside & 1 & 0 & 0 & 0 \\
755 & Lavandulifolioside & 1 & 0 & 0 & 0 \\
801 & Plantamajoside-hexoside & 1 & 1 & 1 & 1 \\
\hline$P m$
\end{tabular}

$P m$ Plantago major, $\mathrm{Pa}$ Plantago australis, $\mathrm{Pl}$ Plantago lanceolata, $P c$ Plantago catharinea

(Table 3). Plantago lanceolata has six metabolites, belonging to the class of flavonoids and phenylethanoid glycosides (Table 3). Plantago catharinea has seven markers of all classes of compounds evaluated (Table 3). These results clearly grouped the Plantago species into three groups composed of: (1) P. major, (2) P. lanceolata and $P$. australis, grouped with $67 \%$ of chemical similarity and (3) $P$. catharinea. These groups are combined with only $20 \%$ of chemical similarity to each other (low similarity). All results of chemical similarity are presented in Fig. 16.

\section{Discussion}

Such minor anatomical differences may be often disregarded in a classical anatomical approach, which presents a real drawback in taxonomic studies. Therefore, new approaches to overcome these disadvantages toward a more universal analysis must be established. Plantago major, $P$. australis, $P$. lanceolata and $P$. catharinea share many anatomical features, such as: amphistomatic epidermis with anomocytic stomata, vascular bundle with the same shape, conspicuous endoderm around the central vascular bundle, smooth cuticle slightly striated, glandular trichomes with two apical cells and tectory trichomes uniseriates, multicellular and tapered. However, the structure of the leaf mesophyll, the anticlinal and periclinal walls, and the secretory structures are diagnostic features of differentiation of each species. Plantago lanceolata has lower anatomical similarity with the others, and it is the only one that shows isolateral mesophyll and collateral vascular bundle.
Regarding the indument, P. major has a different type of glandular trichome, with conspicuous basal cell and collar cell, which was not found in other evaluated species, and therefore it is a diagnostic characteristic of the species. $P$. lanceolata also possesses an exclusive glandular trichome with spindle glandular cells. The amount of glandular trichomes by $\mu \mathrm{m}^{2}$ is also a diagnostic feature, since Plantago lanceolata has less glandular trichomes on the abaxial surface than the other three species. Although these characteristics are changeable with the type of environment, in this work we evaluated plants collected in the same locality and cultivated under the same edaphic system. Therefore, the quantity of epidermal structures and their comparisons only refer to the genetic requirements of each species, so its variations can be considered diagnostic characteristics. Most of pioneer species such as the genus Plantago are amphistomatic (Wilmer and Fricker 1996). It is notable that the number of stomata per area on the abaxial surface appears to be a mechanism to avoid water loss. On the abaxial surface, the temperature tends to be lower than in adaxial, even in the hottest periods of the day (Nicotra et al. 2011). In P. catharinea, this difference was more remarkable because it showed twice the amount of stomata on the abaxial surface when compared to its upper side. This is probably because this species is natural from ecosystems of beaches and dunes, where temperature variations are very high, especially on days with high solar radiance.

Regarding the chemical composition of the species, the same pattern of similarity is not observed. The species are only $20 \%$ similar, proving that despite anatomical similarity, they do not produce the same chemical markers. Our results indicate that $P$. major has all identified chemical markers. Plantago major is the species of the genus most used in the world according to traditional knowledge (Samuelsen 2000), but has only $40 \%$ of chemical similarity to $P$. catharinea, $30 \%$ with $P$. australis and $20 \%$ with $P$. lanceolata. The fact of $P$. major possesses the highest variety of chemical markers evaluated is not sufficient to be recommended for major medicinal use, since quantification experiments are necessary. The Plantago genus is known to possess a wide variety of phenolic compounds such as flavonoids and phenylethanoid glycosides ( $\mathrm{Li}$ et al. 2009; Jankovic et al. 2012), besides iridoid glycosides (Ronsted et al. 2000). In this work, we detected as flavonoid markers apigenin, quercetin and rutin, which have nutraceutical importance, antimicrobial and antiviral properties (Havsteen 2002). The phenylethanoid glycosides show antibacterial activity, cytotoxic, hepatoprotective and immunomodulatory properties (Qi et al. 2012). Glycosides iridoids, such as aucubin, are excellent antioxidants (Ho et al. 2005). According to Ronsted et al. (2000), phenylethanoid glycosides and iridoid glycosides 
are the most representative secondary metabolites of the Plantago genus and are great markers for chemotaxonomic study.

Grubesic et al. (2013) conducted a study with the determination of flavonoids and phenolic acids of eight species of the genus Plantago. Their analysis showed that species, although anatomically similar, have significant differences in the content of polyphenolic compounds and furthermore reported that subspecies of $P$. holosteum do not have the same chemical markers. Zhou et al. (2013) analyzed the chemical composition of 12 species of the genus Plantago and found evidence that species are chemically different. However, Gonda et al. (2010) conducted a screening of bioactive molecules in five species of Plantago and suggested that $P$. altissima and $P$. lanceolata are similar, encouraging that products marketed as $P$. lanceolata can be enriched with $P$. altissima. Therefore, the deficiency in differentiating morphologically similar medicinal species is a real challenge for the standardization of herbal medicines (Garg et al. 2012).

These results demonstrate that the species are anatomically very similar (about 60\%) and do not show the same pattern in its chemical constitution. These evidences prove that the correct botanical identification is very important, since the trade of Plantago herbs, marketed under the same popular name, is a reality. The anatomical and chemical characterization methods used in this work are elucidative and allow distinguishing accurately the main characteristics of each species.

In our study, we applied an approach aiming the differentiation of four morphologically similar Plantago species based on statistical data. Anatomical leaves features were converted into statistical data to allow the characterization and qualitative differentiation between closely related species. Since the increase of the use of modern molecular techniques allied to the development of bioinformatic analysis to taxonomy studies, traditional comparative anatomical studies in order to distinguish species have become of secondary importance. The anatomical results facilitate a valuable taxonomic understanding within the genus and indicate representative characteristics of each species measured by multivariate analysis. Therefore, we reported in this paper the successful use of two approaches-each one showing different refinement levels-for the unambiguous statistical differentiation of the target species. We showed that morphologically very similar species do not always have similar chemical composition and therefore cannot be used for the same medical purpose.

Acknowledgements This project was funded by São Paulo Research Foundation (FAPESP) (2011/23113-0, LMSM and 2009/52237-9, WV).

\section{References}

Atanasov AG, Waltenberger B, Pferschy-Wenzig EM, Linder T, Wawrosch C, Uhrin P, Temml V, Wang L, Schwaiger S, Heiss EH, Rollinger JM, Schuster D, Breuss JM, Bochkov V, Mihovilovic MD, Kopp B, Bauer R, Dirisch VM, Stuppner H (2015) Discovery and resupply of pharmacologically active plant-derived natural products: a review. Biotechnol Adv 33:1582-1614

Danilatos GD (1988) Foundations of environmental scanning electron microscopy. Advances in electronics and electron physics. Academic Press, New York

Ekor M (2013) The growing use of herbal medicines: issues relating to adverse reactions and challenges in monitoring safety. Front Pharmacol 4:177

Garg V, Dhar VJ, Sharma A, Dutt R (2012) Facts about standardization of herbal medicine: a review. Chin J Integr Med 10:1077-1083

Gonda S, Tóth L, Parizsa P, Nyitrai M, Vasas G (2010) Screening of common Plantago species in Hungary for bioactive molecules and antioxidant activity. Acta Biol Hung 61:25-34

Gotelli NJ, Ellison AM (2013) A primer of ecological statistics. Sinauer Associates Inc, Sunderland

Grubesic RJ, Screcnik G, Kremer D, Rodriguez JV, Nikolic T, Vladimir-Knezevic S (2013) Simultaneous RP-HPLC-DAD separation, and determination of flavonoids and phenolic acids in Plantago L. species. Chem Biodivers 10:1305-1316

Halberstein RA (2005) Medicinal plants: historical and cross-cultural usage patterns. Ann Epidemiol 9:686-699

Havsteen BH (2002) The biochemistry and medical significance of the flavonoids. Pharmacol Ther 96:67-202

Hefler SM, Rodrigues WA, Cervi AC (2011) O gênero Plantago L. (Plantaginaceae) na região Sul do Brasil. Rev Bras Biocien 9:297-321

Ho JN, Lee YH, Park JS, Jun WJ, Kim HK, Bum SH, Shin DH, Cho HY (2005) Protective effects of aucubin isolated from Eucommia ulmoides against UVB-induced oxidative stress in human skin fibroblasts. Biol Pharm Bull 28:1244-1248

Jankovic T, Zduníc G, Beara I, Balog K, Pjevljakusic D, Stesevic D, Savikin K (2012) Comparative study of some polyphenols in Plantago species. Biochem Syst Ecol 42:69-74

Johansen DA (1940) Plant microtechnique. Mc Graw Hill, New York

Li L, Chung-Ming L, Zhao-Jie C, Jing W, Dong-Fang S, Zhi-Qiang L (2009) Isolation and purification of Plantamajoside and Acteoside from plant extract of Plantago asiatica L. by hight performance centrifugal partition chromatography. Chem Res Chin Univ 25:817-821

Makhmudov RR, Abdulladzhanova NG, Kamaev FG (2011) Phenolic compounds from Plantago major and P. lanceolata. Chem Nat Compd 42:288-289

Mesquita LMS, Rocha CQ, Affonso LHL, Cerulli A, Piacente S, Tangerina MMP, Martins MBG, Vilegas W (2017) Phenolic Isomers from Plantago catharinea Leaves: Isolation, Identification, Quantification and in vitro Antioxidant Activity. Nat Product Commun 12:409-412

Moreira DL, Teixeira SC, Monteiro MHD, De-Oliveira ACAX, Paumgartten FJR (2014) Traditional use and safety of herbal medicines. Rev Bras Farmacogn 24:248-257

Na-Bangchang K, Karbwang J (2014) Traditional herbal medicine for the control of tropical diseases. Trop Med Health 2:3-13

Nicotra AB, Leigh A, Boyce CK, Jones CS, Niklas KJ, Royer DL, Tsukaya $H$ (2011) The evolution and functional significance of leaf shape in the angiosperms. Funct Plant Biol 38:535-552

O'Brien TP, Feder N, Mccully ME (1964) Polychromatic staining of plant cell walls by toluidine blue O. Protoplasma 59:368-373 
Ozkan G, Kamiloglu S, Ozdal T, Boyacioglu D, Capanoglu E (2016) Potential use of turkish medicinal plants in the treatment of various diseases. Molecules 21:1-32

Prista LN (1995) Tecnologia farmaceutica. Fundação Calouste Gulbenkian, Lisboa

Qi M, Xiong A, Geng F, Yang L, Wang Z (2012) A novel strategy for target profiling analysis of bioactive phenylethanoid glycosides in Plantago medicinal plants using ultra-performance liquid chromatography coupled with tandem quadrupole mass spectrometry. J Sep Sci 35:1470-1478

Ronstead N, Göbel E, Franzyk H, Jensen SR, Olsen CE (2000) Chemotaxonomy of Plantago, Iridoid glucosides and caffeoyl phenylethanoid glycosides. Phytochemistry 22:337-348
Sakai WS (1973) Simple method for differential staining of paraffin embedded plant material using toluidine blue O. Biotech Histochem 48:247-249

Samuelsen AB (2000) The traditional uses, chemical constituents and biological activities of Plantago major L. A review. J Ethnopharmacol 71:1-21

Wilmer C, Fricker M (1996) Stomata. Chapman and Hall, London Zhou Q, Lu W, Niu Y, Liu J, Zhang X, Gao B, Akoh CC, Shi H, Yu LL (2013) Identification and quantification of phytochemical composition, anti-inflammatory, cellular antioxidant and radical scavenging activities of twelve Plantago species. J Agric Food Chem 61:6693-6702 